\title{
Apparent Temperature and Cause-Specific Mortality in Copenhagen, Denmark: A Case-Crossover Analysis
}

\section{Janine Wichmann ${ }^{1, *}$, Zorana Jovanovic Andersen ${ }^{2}$, Matthias Ketzel ${ }^{3}$, Thomas Ellermann ${ }^{3}$ and Steffen Loft ${ }^{1}$}

1 Section of Environmental Health, Institute of Public Health, University of Copenhagen, Øster Farimagsgade 5A, Copenhagen DK-1014, Denmark; E-Mail: stl@sund.ku.dk

2 Institute of Cancer Epidemiology, Danish Cancer Society, 49 Strandboulevarden, Copenhagen DK-2100, Denmark; E-Mail: zorana@cancer.dk

3 Department of Environmental Sciences, Aarhus University, Frederiksborgvej 399, Roskilde DK-4000, Denmark; E-Mails: mke@dmu.dk (M.K.); tel@dmu.dk (T.E.)

* Author to whom correspondence should be addressed; E-Mail: jawic@sund.ku.dk; Tel.: +45-353-27622; Fax: +45-353-27686.

Received: 20 July 2011; in revised form: 22 August 2011 / Accepted: 5 September 2011 / Published: 16 September 2011

\begin{abstract}
Temperature, a key climate change indicator, is expected to increase substantially in the Northern Hemisphere, with potentially grave implications for human health. This study is the first to investigate the association between the daily 3-hour maximum apparent temperature $\left(\operatorname{Tapp}_{\max }\right)$, and respiratory, cardiovascular and cerebrovascular mortality in Copenhagen (1999-2006) using a case-crossover design. Susceptibility was investigated for age, sex, socio-economic status and place of death. For an inter-quartile range $\left(7^{\circ} \mathrm{C}\right)$ increase in Tapp $\max$, an inverse association was found with cardiovascular mortality $(-7 \% 95 \%$ CI $-13 \% ;-1 \%)$ and none with respiratory and cerebrovascular mortality. In the cold period all associations were inverse, although insignificant.
\end{abstract}

Keywords: temperature; epidemiology; respiratory; cardiovascular; cerebrovascular; mortality; case-crossover 


\section{Introduction}

Anthropogenic greenhouse gas emissions are expected to raise average temperatures globally according to the fourth assessment report from the International Panel of Climate Change (IPCC), and consequently the amount of heat-related morbidity and mortality is also likely to increase in Denmark [1]. The evaluations of the relationship between key climate change factors, such as temperature, and health can help identify vulnerable populations and aid policy makers in formulating preventive actions [1].

Numerous studies reported that increased temperature increased total non-accidental mortality, both during specific heat waves [2] and over a long time period, using modern time-series or case-crossover analyses $[3,4]$. Few studies have investigated the relationship between temperature and cause-specific mortality [5-7] or were done in Scandinavia [8-10]. A J-shaped relationship has been found between temperature and total non-accidental and cause-specific mortality, with high temperatures (heat) having an immediate (same day or previous day) effect [3,4]. In a colder climate, the increase of global temperature may benefit health, although the wintertime increase in total non-accidental mortality may be due to infectious disease, and not a direct effect of cold weather [11]. However, few studies have investigated the relationship between decreased temperature and mortality during the colder seasons [12,13]. The overall effect of increased temperature is assumed to depend on cause of death, population characteristics, and efficiency of the health care system. Vulnerability to increased temperature may be affected by socio-economic status (SES), age, sex, level of urbanisation, household characteristics and pre-existing disease status $[3,4]$.

Although the association between air pollution and cardiovascular disease (CVD) and respiratory disease (RD) mortality and morbidity is well established, air pollution has rarely been considered as confounder or effect modifier in studies of temperature effects [2-4]. A recent review concluded that particulate matter less than $10 \mu \mathrm{m}$ in aerodynamic diameter $\left(\mathrm{PM}_{10}\right)$ and ozone could be both, although the independent effect of temperature was usually withheld in analysis taken this into account [4]. Finally, few studies distinguished between in- and out-of-hospital deaths, which may also be important [14,15].

The aim of this study was to investigate the association between the daily 3-hour maximum apparent temperature (Tapp ${ }_{\max }$ ) and RD, CVD and cerebrovascular disease (CBD) mortality. Susceptibility by age, sex, SES and place of death (in- or out-of-hospital) was investigated.

\section{Methods}

\subsection{Mortality and Hospital Admission Data}

Mortality and hospital admission data in the Copenhagen area (postal code $<2930,<15 \mathrm{~km}$ radius from the city centre, population $\approx 1$ million) were retrieved from the Danish cause of death and hospital discharge registers, respectively. The following International Classification of Diseases 10th Revision (ICD 10) codes were included: CVD: angina pectoris (I20), myocardial infarction (I21-22), other acute ischemic heart diseases (I24), chronic ischemic heart disease (I25), pulmonary embolism (I26), cardiac arrest (I46), cardiac arrhythmias (I48-49), and heart failure (I50); CBD: intracerebral haemorrhage (I61), cerebral infarction (I62) and stroke, not specified as haemorrhage or infarction (I64); $R D$ : 
chronic bronchitis (J41-42), emphysema (J43), chronic obstructive pulmonary disease (J44), asthma (J45) and status asthmaticus (J46).

Only primary diagnosed hospital admissions were included as outcome, but both emergency and planned hospital admissions were linked to the mortality dataset. A death was classified as in-hospital, when the hospital discharge date was the same as the date of death, and out-of-hospital when the hospital discharge date was at least one day before the date of death. Twelve deaths could not be classified due to errors in hospital discharge dates (after death).

\subsection{Meteorological and Air Pollution Data}

Meteorological and air pollution data were measured at the Copenhagen urban background monitoring station by the Department of Environmental Sciences, Aarhus University [16]. Temperature and relative humidity (RH) were measured with the HMP45a probe (Vaisala, Helsinki). Air pollution data included 24-hour averages (from midnight to midnight) of $\mathrm{PM}_{10}$ (Beta attenuation by SM200 monitor; Opsis, Sweden), nitrogen dioxide $\left(\mathrm{NO}_{2}\right)$ (M 200A; API, San Diego, CA, USA) and carbon monoxide (CO) (M 300 monitor; API). $\mathrm{NO}_{2}$ was also reported as a daily 1-hour maximum $\left(\mathrm{NO}_{2 \max }\right)$. The $\mathrm{RH}$ measurements have a minor error probably due to the calibration, which had a minor impact on the calculated Tapp $\mathrm{max}_{\text {ax }}$. Hence this measurement error is not likely to reduce the validity of our results (Supplementary Figures 1 and 2).

Barnett and colleagues concluded that there is no single temperature measure that is superior to others [17]. We selected Tapp $p_{\max }$ as the primary exposure variable. Tapp $\mathrm{p}_{\max }$ is a construct intended to reflect the physiological experience of combined exposure to humidity and temperature and thereby better capture the response on health than temperature alone [18]. Tapp $p_{\max }$ has been applied in several studies [2-4].

\subsection{Influenza Data}

Influenza epidemics data were provided by the National Serum Institute as weekly percentage of total general physician's consultations due to influenza in Denmark, whereas city level data were not available.

\subsection{Effect Modifier Data}

Addresses of the 31,342 deceased persons were retrieved by linkage with the Danish central population registry. A recent report was published on SES groups in Copenhagen, which classified communities and the inner city neighbourhoods into four SES groups (highest, second highest, second lowest and lowest), based on household income, educational and employment status [19]. An area SES class was assigned to each person by linking the home street code to a geographical information system dataset. Nearly all (99\%) of the 31,342 deceased persons lived at only one address during 1999-2006. A SES class could not be assigned to 456 people due to invalid street codes. A SES code was assigned for the valid address at which the person lived longest. In the case of more than three addresses, the mode of the area SES classes at the different addresses was assigned to that person. 


\subsection{Ethics}

As this study was purely registry based, no human participants were recruited or included in experiments. Approval was granted by the proper authority, which in this case is the Danish Data Protection Agency.

\subsection{Statistical Analysis}

The time-stratified case-crossover design was applied to investigate the association between Tapp $\max$ and the cause-specific mortality (in- and/or out-of-hospital) for the period 1 January 1999-31 December 2006. The case-crossover design was developed as a variant of the case-control design to study the effects of transient exposures on emergency events [20]. In this design each person's exposure is compared in a time period just prior to a case-defining event with his/her exposure at other times [20]. Hereby, control on all measured and unmeasured personal characteristics that do not vary over a short time period is accomplished. If in addition, the control days are chosen close to the event day, personal characteristics that vary slowly over time are also controlled by matching. A time-stratified approach was applied to select the control days, defining the day of death as the case day and same day of the week in the same month and year as control days. Hence, for example, if someone died on 16 February 2000, then the control days would have been the 2, 9, 23 February 2000. With this approach even very strong confounding of exposure by seasonal patterns is controlled by design [21-24]. The association between Tapp max $_{\text {and }}$ and the cause-specific mortality were investigated using conditional logistic regression analysis (PROC PHREG in SAS 9.2, SAS Institute, Cary, NC, USA).

Models were first stratified by seasonal period (warm or cold). Public holidays were controlled for as a dichotomous variable and influenza as a continuous variable. A previous study in Copenhagen reported a linear relationship between the air pollutants and the cause-specific admissions for the period 1999-2004 [25]. The pollutants were therefore modeled as linear terms, one pollutant at a time. During 1999-2006 there were 569 and 114 days with missing values for the pollutants and meteorological variables, respectively, with a total of 625 days with missing data out of 2,922.

Individual lags of lag0 (same day exposure as day of death) to lag5 (exposure five days prior to day

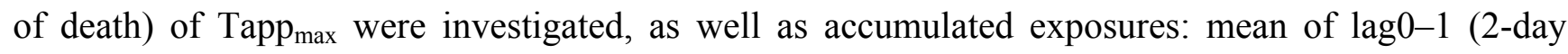
simple unweighted cumulative average, CA2), and up to mean lag0-5 (CA6). Control days for lag1 to 5 were defined as for lag0. The same lag of Tapp $\max$ and an air pollutant was included in a model.

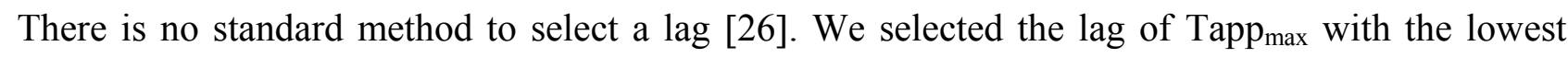
Akaike Information Criterion (AIC) and applied that in the stratified models. In general, the lowest AIC model had the strongest association (i.e., highest absolute association measure) between Tapp $\mathrm{p}_{\max }$ and a cause-specific outcome.

A large European study observed associations between mortality and longer lags of up to CA15 for the cold period [13]. Hence, longer lags of up to CA15 for the cold period were also investigated in our study.

Hazard ratios (HR) and the 95\% confidence intervals (CI) were calculated per inter-quartile range (IQR) increase in $\operatorname{Tapp}_{\max }\left(\right.$ in ${ }^{\circ} \mathrm{C}$ ). The results are presented as the percent excess risk in cause-specific 
mortality per IQR increase in Tapp $\max$ using the following calculation: $\beta^{(\mathrm{HR}-1) \times 100 \%}$, where $\beta$ is the model estimate.

Due to the nature of the case-crossover design where each person is his/her own control, susceptibility cannot be investigated by including an interaction term between the susceptibility

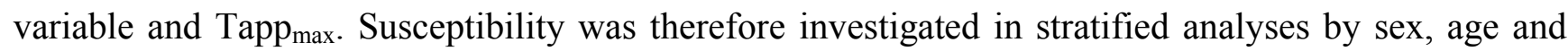
SES groups. Age was categorised as $19-65,66-80$ and $>80$ years.

Sensitivity analyses were applied. The linearity and strength of the association between Tapp $p_{\max }$ and a cause-specific outcome were substantiated in generalised additive Poisson time-series regression models (GAM) with the use of the gam procedure, $m g c v$ package in $\mathrm{R}$ statistical software (R Development Core Team, 2010). Models were run with linear and non-linear terms for Tapp $\mathrm{p}_{\max }$, as a natural smoothing spline function with five degrees of freedom (df). Smoothing splines of calendar time ( $4 \mathrm{df} /$ year) were used to control for long-term trend and seasonality. A spline function, defined by piecewise polynomials, has a flexible shape that is useful for adjusting for non-linear effects. The smoothness of a spline is a function of the number of degrees of freedom. We investigated whether the

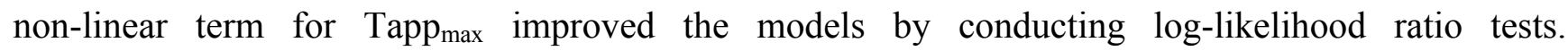
Unmeasured, unknown and potentially variable seasonal and long term patterns need to be controlled for adequately in GAM models, whilst still leaving sufficient information from which to estimate temperature effects. Other sensitivity analyses included applying the 24-hour average temperature $\left(\mathrm{T}_{\mathrm{ave}}\right)$ as an alternative temperature definition, whilst also adjusting for the 24-hour average $\mathrm{RH}$, public holidays and influenza epidemic.

\section{Results}

The statistical analyses are based on 2,922 days with 5,973 RD, 18,816 CVD and 6,558 CBD deaths. Table 1 displays a summary of the meteorological conditions, air pollution levels and influenza epidemics during 1999-2006. None of the EU air quality limit values $\left(\mathrm{PM}_{10} 40 \mu \mathrm{g} . \mathrm{m}^{-3}\right.$ (annual), $\mathrm{NO}_{2}$ $21 \mathrm{ppb}$ (annual), CO $5.3 \mathrm{ppm}$ (1-hour max)) were exceeded at the urban background level, but $\mathrm{PM}_{10}$ and $\mathrm{NO}_{2}$ limit values were exceeded at street level (not shown) [27].

Table 1. Summary statistics for cause-specific mortality, air pollutant levels and meteorological conditions in Copenhagen and weekly general practice visits due to influenza in Denmark during 1 January 1999-31 December 2006.

\begin{tabular}{llll}
\hline & All year & Warm period & Cold period \\
\hline $\begin{array}{l}\text { Number of days } \\
\text { Respiratory deaths }\end{array}$ & 2,922 & 1,464 & 1,458 \\
Mean \pm SD & $2 \pm 2$ & & \\
Range & $0-10$ & $2 \pm 1$ & $2 \pm 2$ \\
\hline
\end{tabular}


Table 1. Cont.

\begin{tabular}{|c|c|c|c|}
\hline & All year & Warm period & Cold period \\
\hline \multicolumn{4}{|l|}{ Cardiovascular deaths } \\
\hline Mean \pm SD & $6 \pm 3$ & $6 \pm 3$ & $7 \pm 3$ \\
\hline Range & $0-18$ & $0-15$ & $0-18$ \\
\hline \multicolumn{4}{|l|}{ Cerebrovascular deaths } \\
\hline Mean \pm SD & $2 \pm 2$ & $2 \pm 2$ & $2 \pm 2$ \\
\hline Range & $0-10$ & $0-9$ & $0-10$ \\
\hline \multicolumn{4}{|l|}{$\operatorname{Tapp}_{\max }\left({ }^{\circ} \mathrm{C}\right)$} \\
\hline $\begin{array}{l}\text { Number of days with } \\
\text { missing data }\end{array}$ & 114 & 32 & 82 \\
\hline Mean \pm SD & $10 \pm 8$ & $16 \pm 6$ & $4 \pm 5$ \\
\hline Range & $-8-30$ & $0-30$ & $-8-18$ \\
\hline \multicolumn{4}{|l|}{ Percentiles } \\
\hline 25 th & 3 & 12 & 0 \\
\hline 50 th & 9 & 16 & 3 \\
\hline 75th & 16 & 20 & 7 \\
\hline Inter-quartile range & 13 & 8 & 7 \\
\hline \multicolumn{4}{|l|}{$\mathrm{PM}_{10}\left(\mu \mathrm{g} / \mathrm{m}^{3}\right)$} \\
\hline $\begin{array}{l}\text { Number of days with } \\
\text { missing data }\end{array}$ & 454 & 266 & 188 \\
\hline Mean \pm SD & $27 \pm 16$ & $27 \pm 14$ & $28 \pm 17$ \\
\hline Range & $0-284$ & $1-284$ & $0-248$ \\
\hline \multicolumn{4}{|l|}{$\mathrm{NO}_{2}(\mathrm{ppb})$} \\
\hline $\begin{array}{l}\text { Number of days with } \\
\text { missing data }\end{array}$ & 164 & 109 & 55 \\
\hline Mean \pm SD & $12 \pm 5$ & $11 \pm 4$ & $13 \pm 5$ \\
\hline Range & $2-41$ & $3-33$ & $2-41$ \\
\hline \multicolumn{4}{|l|}{$\mathrm{NO}_{2 \max }(\mathrm{ppb})$} \\
\hline $\begin{array}{l}\text { Number of days with } \\
\text { missing data }\end{array}$ & 137 & 97 & 40 \\
\hline Mean \pm SD & $22 \pm 9$ & $21 \pm 10$ & $23 \pm 9$ \\
\hline Range & $4-78$ & $4-78$ & $5-60$ \\
\hline \multicolumn{4}{|l|}{$\mathrm{CO}$ (ppm) } \\
\hline $\begin{array}{l}\text { Number of days with } \\
\text { missing data }\end{array}$ & 129 & 81 & 48 \\
\hline Mean \pm SD & $0.28 \pm 0.10$ & $0.23 \pm 0.07$ & $0.33 \pm 0.10$ \\
\hline Range & $0.08-0.92$ & $0.08-0.58$ & $0.13-0.92$ \\
\hline \multicolumn{4}{|l|}{$\begin{array}{l}\text { Weekly GP visits due to } \\
\text { influenza in Denmark (\%) }\end{array}$} \\
\hline $\begin{array}{l}\text { Number of weeks with } \\
\text { missing data }\end{array}$ & 0 & 0 & 0 \\
\hline Mean \pm SD & $1.12 \pm 1.50$ & $0.28 \pm 0.61$ & $1.96 \pm 1.65$ \\
\hline Range & $0-9.70$ & $0-3.40$ & $0-9.70$ \\
\hline
\end{tabular}

SD: Standard deviation; GP: General practitioner. 
The majority of deaths were due to CVD, followed by CBD and RD, with more deaths during the cold period (Table 1). The majority of in-hospital RD, CVD and CBD deaths occurred after emergency hospital admissions: $93 \%, 97 \%$ and $96 \%$, respectively. Half of the RD and CBD deaths occurred in-hospital, whilst $66 \%$ of CVD deaths were out-of-hospital (Table 2). Regardless of place of death, the majority of RD deaths were due to chronic obstructive pulmonary disease. In-hospital CVD deaths were mostly due to acute health outcomes compared to out-of-hospital CVD deaths. Regardless of place of death, the majority of the CBD deaths were due to stroke, not specified as haemorrhage or infarction.

Table 2. Summary statistics for specific types of respiratory, cardiovascular and cerebrovascular deaths, by place of death during 1 January 1999-31 December 2006.

\begin{tabular}{|c|c|c|c|c|c|c|}
\hline & \multicolumn{2}{|c|}{$\begin{array}{l}\text { In-hospital } \\
\text { deaths }\end{array}$} & \multicolumn{2}{|c|}{$\begin{array}{l}\text { Out-of-hospital } \\
\text { deaths }\end{array}$} & \multicolumn{2}{|l|}{ Total * } \\
\hline & No. & $\%$ & No. & $\%$ & No. & $\%$ \\
\hline Repiratory deaths & 3,089 & 100.0 & 2,883 & 100.0 & 5,973 & 100.0 \\
\hline $\begin{array}{l}\text { Simple and mucopurulent chronic } \\
\text { bronchitis }\end{array}$ & 0 & 0.0 & 7 & 0.2 & 7 & 0.1 \\
\hline Unspecified chronic bronchitis & 156 & 5.1 & 313 & 10.9 & 469 & 7.9 \\
\hline Emphysema & 44 & 1.4 & 73 & 2.5 & 117 & 2.0 \\
\hline $\begin{array}{l}\text { Chronic obstructive pulmonary } \\
\text { disease }\end{array}$ & 2,857 & 92.5 & 2,192 & 76.0 & 5,049 & 84.5 \\
\hline Asthma & 26 & 0.8 & 288 & 10.0 & 314 & 5.3 \\
\hline Status astmaticus & 6 & 0.2 & 10 & 0.3 & 16 & 0.3 \\
\hline Cardiovascular deaths & 6,310 & 100.0 & 12,502 & 100.0 & 18,816 & 100.0 \\
\hline Angina pectoris & 26 & 0.4 & 61 & 0.5 & 87 & 0.5 \\
\hline Acute myocardial infarction & 2,517 & 39.9 & 3,064 & 24.5 & 5,581 & 29.7 \\
\hline Subsequent myocardial infarction & 154 & 2.4 & 165 & 1.3 & 319 & 1.7 \\
\hline Other acute ischemic heart diseases & 8 & 0.1 & 8 & 0.1 & 16 & 0.1 \\
\hline Chronic ischemic heart disease & 1,387 & 22.0 & 5,244 & 41.9 & 6,631 & 35.2 \\
\hline Pulmonary embolism & 337 & 5.3 & 304 & 2.4 & 641 & 3.4 \\
\hline Cardiac arrest & 143 & 2.3 & 1,013 & 8.1 & 1,156 & 6.1 \\
\hline Atrial fibrillation and flutter & 544 & 8.6 & 496 & 4.0 & 1,040 & 5.5 \\
\hline Other cardiac arrhythmias & 27 & 0.4 & 92 & 0.7 & 119 & 0.6 \\
\hline Heart failure & 1,167 & 18.5 & 2,055 & 16.4 & 3,222 & 17.1 \\
\hline Cerebrovascular deaths & 3,469 & 100.0 & 3,082 & 100.0 & 6,558 & 100.0 \\
\hline Intracerebral haemorrhage & 1,128 & 32.5 & 389 & 12.6 & 1,517 & 23.1 \\
\hline Cerebral infarction & 595 & 17.2 & 345 & 11.2 & 940 & 14.3 \\
\hline $\begin{array}{l}\text { Stroke, not specified as haemorrhage } \\
\text { or infarction }\end{array}$ & 1,746 & 50.3 & 2,348 & 76.2 & 4,094 & 62.4 \\
\hline Total & 12,868 & & 18,467 & & 31,347 & \\
\hline
\end{tabular}

* One, four and seven RD, CVD and CBD deaths could not be classified as in- or out-of-hospital deaths, due to errors in hospital discharge dates (after death). 
Supplementary Figure 3 indicates the average number of cause-specific deaths per Tapp $\max _{\max }(\operatorname{lag} 0)$. We did not observe a Tapp $\max$ threshold in Copenhagen for which a minimum number of cause-specific deaths occurred. We therefore split a year into a warm and cold period. The warm and cold periods were defined as April-September and October-March, respectively, as for in other European cities $[2,4,18,28]$. Below $9{ }^{\circ} \mathrm{C}$ most days were in the cold period and at $9{ }^{\circ} \mathrm{C}$ or above most days were in the warm period (Supplementary Figure 4). So overlap of Tapp $p_{\max }$ in the warm and cold periods was minimal.

CA6 of Tapp max $_{\text {ax }}$ was selected as lag and applied in the stratified models (Supplementary Figure 5). In general no significant associations were observed between the air pollutants and RD, CVD or CBD mortality during 1999-2006; specifically not for the selected lag of Tapp $\max$, i.e., CA6. (Supplementary Figures 6 and 7). Consequently the models were not adjusted for any of the air pollutants (Tables 3 and 4). The air pollutant models were adjusted for Tapp $p_{\max }$ (same lag as pollutant), public holidays and influenza.

An IQR increase in the CA6 of Tapp $p_{\max }$ in the warm period was associated with an insignificant increase of $6 \%$ in RD mortality (Table 3). For an IQR increase in the CA6 of Tapp max $_{\text {mere was a }}$ significant decrease of $7 \%$ in CVD mortality during the warm period (Table 3). The association between Tapp $\mathrm{max}_{\max }$ and CVD mortality was stronger for those $>80$ years and those in the lowest SES group. There was no association between the CA6 of Tapp $p_{\max }$ in the warm period and CBD mortality (Table 3).

In the cold period, the associations with the CA6 of Tapp $\mathrm{max}_{\max }$ were inverse, yet insignificant (Table 4). However, for RD the association reached significance for out-of-hospital deaths. For CVD and CBD, the association with Tapp $p_{\max }$ reached significance in the highest and lowest SES groups, respectively.

The effect estimate of the subgroup analyses had a wide $95 \%$ CI due to the small sample sizes. The direction of the observed associations was confirmed in the GAM analyses (Table 5). The parameter estimates for the confounders (influenza, public holiday) were similar in the GAM and case-crossover analyses.

We did not find any evidence of a significant delayed effect after 6 days cumulative exposure in the cold period (Figure 1). The effect of cold on RD and CBD mortality appears to be stronger after 6 days cumulative exposure (CA6), but did not reach significance. We thus reported results for only up to CA6.

$\mathrm{T}_{\mathrm{ave}}$ had similar associations with cause-specific mortality than Tapp $\max$, with or without adjusting for 24-hour average RH (Supplementary Figures 8-10). 
Table 3. Association between Tapp $\max$ (in ${ }^{\circ} \mathrm{C}$ ) and mortality, by cause of death, expressed as percentage increase in risk $(\%)$ and $95 \%$ confidence intervals per inter-quartile increase in the 6-day cumulative average of Tapp ${ }_{\max }\left(\right.$ in $\left.{ }^{\circ} \mathrm{C}\right)$ during warm period of 1 January 1999 31 December 2006 in Copenhagen.

\begin{tabular}{|c|c|c|c|c|c|c|c|c|c|c|c|c|c|c|c|}
\hline \multirow[b]{3}{*}{ All } & \multicolumn{5}{|c|}{ Respiratory disease } & \multicolumn{5}{|c|}{ Cardiovascular disease } & \multicolumn{5}{|c|}{ Cerebrovascular disease } \\
\hline & \multirow{2}{*}{$\begin{array}{l}\text { IQR } \\
7\end{array}$} & \multirow{2}{*}{$\begin{array}{l}\mathbf{n} \\
2,431\end{array}$} & \multirow{2}{*}{$\begin{array}{c}\% \\
6.3\end{array}$} & \multicolumn{2}{|c|}{$95 \%$ CI } & \multirow{2}{*}{$\begin{array}{l}\text { IQR } \\
7\end{array}$} & \multirow{2}{*}{$\begin{array}{l}\mathbf{n} \\
7,976\end{array}$} & \multirow{2}{*}{$\begin{array}{l}\% \\
-6.9\end{array}$} & \multicolumn{2}{|c|}{$95 \% \mathrm{CI}$} & \multirow{2}{*}{$\begin{array}{l}\text { IQR } \\
7\end{array}$} & \multirow{2}{*}{$\begin{array}{l}\mathbf{n} \\
2,834\end{array}$} & \multirow{2}{*}{$\begin{array}{l}\% \\
2.0\end{array}$} & \multicolumn{2}{|c|}{$95 \%$ CI } \\
\hline & & & & -5.4 & 19.4 & & & & -12.7 & -0.6 & & & & -8.6 & 13.8 \\
\hline \multicolumn{16}{|l|}{ Age categories } \\
\hline$\leq 65$ years & 8 & 234 & -3.7 & -36.5 & 46.1 & 7 & 871 & 7.5 & -11.3 & 30.4 & 7 & 249 & 21.3 & -16.7 & 76.7 \\
\hline $66-80$ years & 7 & 1,145 & 5.3 & -11.1 & 24.8 & 7 & 2,225 & -9.0 & -19.5 & 2.9 & 7 & 788 & 7.1 & -12.8 & 31.6 \\
\hline$>80$ years & 8 & 1,052 & 12.3 & -8.4 & 37.6 & 7 & 4,880 & -8.3 & -15.7 & -0.4 & 7 & 1,797 & -2.6 & -15.2 & 11.9 \\
\hline \multicolumn{16}{|l|}{ Sex } \\
\hline Women & 7 & 1,422 & 1.0 & -13.3 & 17.7 & 7 & 4,286 & -4.9 & -13.0 & 3.9 & 7 & 1,780 & 1.0 & -12.2 & 16.2 \\
\hline Men & 8 & 1,009 & 16.3 & -5.2 & 42.8 & 7 & 3,690 & -9.1 & -17.4 & 0.0 & 7 & 1,054 & 3.9 & -13.0 & 24.0 \\
\hline \multicolumn{16}{|l|}{$\begin{array}{l}\text { Socio-economic } \\
\text { status }\end{array}$} \\
\hline Lowest & 7 & 882 & 4.8 & -13.7 & 27.4 & 7 & 2,667 & -11.2 & -20.7 & -0.6 & 7 & 876 & 13.6 & -6.8 & 38.3 \\
\hline Second lowest & 8 & 677 & -12.5 & -31.9 & 12.4 & 7 & 2,000 & -6.7 & -17.9 & 6.0 & 7 & 725 & -5.4 & -23.7 & 17.4 \\
\hline Second highest & 8 & 572 & 30.2 & -0.7 & 70.7 & 8 & 2,166 & -1.5 & -14.7 & 13.6 & 7 & 801 & -10.5 & -27.3 & 10.2 \\
\hline Highest & 8 & 265 & 20.8 & -19.6 & 81.5 & 7 & 1,034 & -7.0 & -22.5 & 11.6 & 8 & 396 & 16.0 & -17.5 & 63.1 \\
\hline \multicolumn{16}{|l|}{ Place of death } \\
\hline In-hospital & 8 & 1,242 & 1.1 & -16.0 & 21.7 & 7 & 2,629 & -9.4 & -19.1 & 1.4 & 7 & 1,488 & -7.0 & -20.2 & 8.4 \\
\hline Out-of-hospital & 7 & 1,188 & 12.1 & -5.1 & 32.5 & 7 & 5,345 & -5.6 & -12.8 & 2.2 & 7 & 1,342 & 11.5 & -4.8 & 30.7 \\
\hline
\end{tabular}

* Adjusted for day of the week, public holidays and influenza rates. 
Table 4. Association between Tapp $\max$ (in ${ }^{\circ} \mathrm{C}$ ) and mortality, by cause of death, expressed as percentage increase in risk (\%) and $95 \%$ confidence intervals per inter-quartile increase in the 6-day cumulative average of $\mathrm{Tapp}_{\max }\left(\right.$ in ${ }^{\circ} \mathrm{C}$ ) during cold period of 1 January 1999 31 December 2006 in Copenhagen.

\begin{tabular}{|c|c|c|c|c|c|c|c|c|c|c|c|c|c|c|c|}
\hline & \multicolumn{5}{|c|}{ Respiratory disease } & \multicolumn{5}{|c|}{ Cardiovascular disease } & \multicolumn{5}{|c|}{ Cerebrovascular disease } \\
\hline & IQR & n & $\%$ & $95 \%$ & & IQR & $\mathrm{n}$ & $\%$ & $95 \% \mathrm{C}$ & & IQR & $\mathbf{n}$ & $\%$ & $95 \% \mathrm{C}$ & \\
\hline All & 6 & 2,854 & -4.8 & -13.9 & 5.4 & 6 & 8,777 & -2.7 & -8.2 & 3.1 & 6 & 3,010 & -2.5 & -11.7 & 7.6 \\
\hline \multicolumn{16}{|l|}{ Age categories } \\
\hline$\leq 65$ years & 6 & 318 & 4.7 & -22.7 & 41.8 & 6 & 927 & -13.7 & -28.0 & 3.5 & 7 & 221 & 26.1 & -15.5 & 88.1 \\
\hline $66-80$ years & 6 & 1,349 & 1.9 & -12.1 & 18.2 & 6 & 2,415 & 5.9 & -5.2 & 18.2 & 6 & 885 & -1.6 & -18.1 & 18.1 \\
\hline$>80$ years & 6 & 1,187 & -13.4 & -25.9 & 1.2 & 6 & 5,435 & -4.5 & -11.3 & 2.8 & 6 & 1,904 & -5.7 & -16.8 & 6.8 \\
\hline \multicolumn{16}{|l|}{ Sex } \\
\hline Women & 6 & 1,720 & -1.7 & -13.6 & 12.0 & 6 & 4,769 & -0.3 & -7.8 & 7.9 & 6 & 1,970 & -0.3 & -11.9 & 12.8 \\
\hline Men & 6 & 1,134 & -9.3 & -22.8 & 6.5 & 6 & 4,008 & -5.6 & -13.3 & 2.9 & 6 & 1,040 & -6.0 & -20.3 & 10.8 \\
\hline \multicolumn{16}{|l|}{$\begin{array}{l}\text { Socio-economic } \\
\text { status }\end{array}$} \\
\hline Lowest & 6 & 1,034 & -6.2 & -20.2 & 10.4 & 6 & 2,996 & -2.1 & -11.3 & 8.1 & 6 & 937 & -19.2 & -32.4 & -3.5 \\
\hline Second lowest & 6 & 744 & -1.2 & -19.7 & 21.5 & 6 & 2,121 & 0.5 & -10.7 & 13.0 & 6 & 807 & 11.8 & -7.6 & 35.3 \\
\hline Second highest & 6 & 701 & -10.8 & -27.2 & 9.4 & 6 & 2,362 & 0.3 & -10.3 & 12.1 & 6 & 806 & -2.8 & -19.9 & 17.8 \\
\hline Highest & 6 & 341 & 4.5 & -22.1 & 40.2 & 6 & 1,144 & -16.2 & -28.5 & -1.7 & 6 & 419 & 11.1 & -14.3 & 44.2 \\
\hline \multicolumn{16}{|l|}{ Place of death } \\
\hline In-hospital & 6 & 1,494 & 5.0 & -8.7 & 20.7 & 6 & 2,978 & -6.8 & -15.6 & 2.8 & 6 & 1,603 & -4.5 & -16.6 & 9.2 \\
\hline Out-of-hospital & 6 & 1,360 & -14.4 & -26.0 & -0.9 & 6 & 5,797 & -0.6 & -7.4 & 6.8 & 6 & 1,406 & 0.0 & -13.5 & 15.7 \\
\hline
\end{tabular}

* Adjusted for day of the week, public holidays and influenza rates.

Table 5. Association between Tapp $\max \left(\right.$ in ${ }^{\circ} \mathrm{C}$ ) and mortality, by cause of death, expressed as percentage increase in risk (\%) and $95 \%$ confidence intervals per inter-quartile increase in the 6-day cumulative average of Tapp max $_{(i n}{ }^{\circ} \mathrm{C}$ ) during 1 January $1999-31$ December 2006 in Copenhagen.: Generalised additive Poisson time-series regression models.

\begin{tabular}{|c|c|c|c|c|c|c|c|c|c|c|c|c|c|c|c|}
\hline & \multicolumn{5}{|c|}{ Respiratory disease } & \multicolumn{5}{|c|}{ Cardiovascular disease } & \multicolumn{5}{|c|}{ Cerebrovascular disease } \\
\hline & IQR & $n *$ & $\%$ & $95 \%$ & & IQR & n & $\%$ & $95 \%$ & & IQR & $\mathbf{n}$ & $\%$ & $95 \%$ & \\
\hline Warm & 7 & 1,342 & 3.3 & -5.4 & 12.8 & 7 & 1,342 & -4.4 & $\begin{array}{l}-8.9 \\
\end{array}$ & 0.4 & 7 & 1,342 & -1.3 & -9.1 & 7.2 \\
\hline Cold & 6 & 1,271 & -8.0 & -14.1 & -1.5 & 6 & 1,271 & -7.5 & -10.9 & -4.0 & 6 & 1,271 & -0.9 & -7.3 & 6.0 \\
\hline
\end{tabular}

Models adjusted for calendar time (4 df/year), day of the week, public holidays and influenza rates.

* Number of days in GAM. Fewer days than in Table 1 due to missing data for 6-day cumulative average of Tapp max $_{\text {. }}$ 
Figure 1. Percentage change (95\% CI) in cause-specific mortality in Copenhagen per interquartile range increase in Tapp $p_{\max }$ during the cold period* (1 January 199931 December 2006), adjusted for public holidays and influenza.
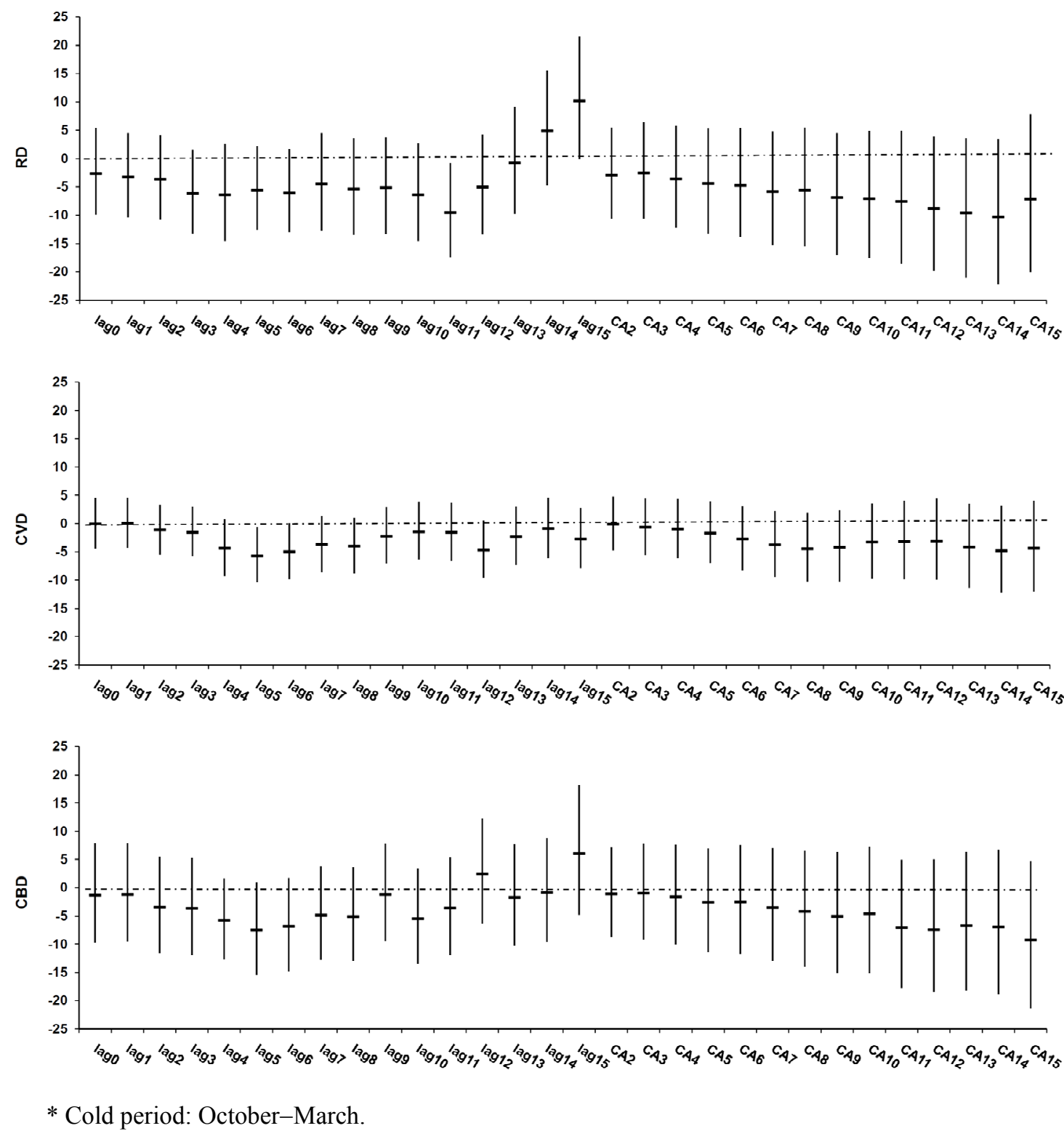

\section{Discussion}

We evaluated associations between Tapp $\mathrm{max}_{\max }$ and RD, CVD and CBD mortality in Copenhagen for the period 1999-2006. We found an apparent modest effect of increasing temperature on six subtypes of RD mortality of $0.9 \%$ per $1{ }^{\circ} \mathrm{C}$ increase in the warm period. Swedish and Norwegian studies reported stronger associations between total RD mortality (all ICD10 codes $\mathrm{J}$ and any place of death) and the average daily temperature $\left(\mathrm{T}_{\text {ave }}\right)>11^{\circ} \mathrm{C}\left(4.3 \%\right.$ per $1{ }^{\circ} \mathrm{C}$ increase $)$ and $>10{ }^{\circ} \mathrm{C}\left(4.7 \%\right.$ per $1{ }^{\circ} \mathrm{C}$ increase in $\mathrm{T}_{\text {ave }}$ over the last 7 days), respectively [8-10]. An aggregated analysis of North-Continental

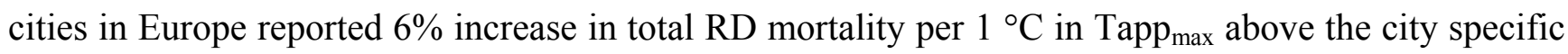
threshold [29,30]. Our lag structure with main apparent effects on RD mortality occurring within 
5 days and increased susceptibility among the elderly corroborates the findings of North-Continental European cities $[29,30]$.

We observed an inverse association between Tapp $p_{\max }$ and the 10 subtypes of CVD mortality in the warm period: $-1.0 \%$ per $1{ }^{\circ} \mathrm{C}$ increase or alternatively, $1.0 \%$ per $1{ }^{\circ} \mathrm{C}$ decrease. A Swedish study reported a weak yet positive association between total CVD mortality (all ICD10 codes I, and any place of death) and $\mathrm{T}_{\mathrm{ave}}>11{ }^{\circ} \mathrm{C}\left(1.1 \%\right.$ per $1{ }^{\circ} \mathrm{C}$ increase) [10]. In the North-Continental European cities total CVD mortality increased by $2 \%$ with Tapp max [29,30]. Of these cities only Dublin showed an apparently protective effect of high temperature on total mortality. Copenhagen and Dublin have quite a similar climate in the warm period [29] and it is possible that cool and rainy weather have more adverse effect on CVD mortality than the few high temperature surges.

The lack of association between Tapp max $_{\max }$ and the three subtypes of CBD mortality in the warm period in Copenhagen is consistent with the findings from a large multinational European study [29]. We observed signs of protective effects of high temperature on all three causes of mortality during the cold season, consistent with other studies [5,8,12-14].

We did not observe a Tapp $\max$ threshold in Copenhagen for which a minimum number of cause-specific deaths occurred (Supplementary Figure 3). However, the weight (number of days) of each Tapp $p_{\max }$ is different and is taken into account in regression analyses. An insignificant linear negative and positive relationship between RD deaths, and Tapp $p_{\max }$ was observed during the cold and warm periods, respectively. For CVD deaths a negative relationship was observed during both periods, although insignificant in the cold period. However, these weak associations are related to the absolute

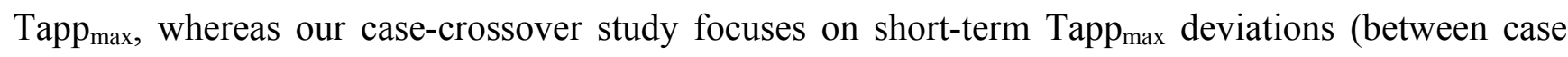
and control days) within a limited period of one month.

Studies investigating susceptibility, other than age, of the temperature and cause-specific mortality relationship are scarce. We did not observed any significant adverse effect of Tapp max $_{\text {on }}$ RD and CBD mortality by age, gender, SES or place of death in the warm period. For CVD mortality, the elderly and lowest SES group were more susceptible to increases in Tapp $p_{\max }$ in the warm period. Other studies reported a stronger association between total non-accidental mortality and increased temperature during specific heat waves and ordinary periods among the elderly, lower SES groups and women [6,15,31]. Total non-accidental mortality includes deaths from a broad spectrum of causes with probable variability in sensitivity. A study that focused on extreme heat events reported a rapid increase in out-of-hospital non-accidental deaths, especially amongst the oldest groups [14] No extreme or long-lasting heat waves occurred in Copenhagen during 1999-2006 and this might be a possible reason why we did not observe an increase of out-of-hospital cause-specific deaths with increasing Tapp $\mathrm{max}_{\max }$.

The underlying mechanisms for increases in RD, CVD and CBD deaths after exposure to high temperatures may be due to blood flow shifts to subcutaneous areas and away from the vital organs, in an effort to cool the body [2-4]. Increased blood viscosity due to dehydration, elevated cholesterol levels and a higher sweating threshold in the elderly may trigger heat-related mortality in susceptible individuals. Factors that hamper sweating, such as high ambient humidity, reduced air currents or anticholinergic drugs reduce resistance to high temperature $[2,4]$. 
Various mechanisms are proposed to explain the increase in CVD and CBD mortality with decreasing temperatures in the cold season, such as an increase in platelet and red cell counts, blood viscosity and arterial pressure [32]. Elderly and the lowest SES groups are likely to be particularly susceptible to such cold effects compatible with our data for CBD, whereas our data on CVD showed different patterns.

Although we found no significant association between any of the air pollutants (for CA6) and cause-specific mortality, the effect estimates for lag0 of $\mathrm{PM}_{10}$ (per $10 \mu \mathrm{g} \cdot \mathrm{m}^{-3}$ increase) and $\mathrm{RD}$ and CVD mortality in the cold and warm periods are similar to those of the latest meta-analysis (all year): 1.3\% (95\% CI 0.05\%; 0.2\%; pooled 18 European studies) and 0.9\% (95\% CI 0.05\%; 1.3\%; pooled 17 European studies), respectively [26]. Our 95\% CIs are wider though. A significant association between $\mathrm{PM}_{10}$ and all cause mortality were observed for only 12 of the 33 urban centres used in the $\mathrm{PM}_{10}$ meta-analysis. $\mathrm{PM}_{10}$ was found to be an effect modifier in Australia and a confounder in Mexico and in regions throughout the United States, especially in the summer [4]. None of the other Scandinavian studies considered air pollutants as confounders or effect modifiers [8-10].

We did not find any evidence of a significant delayed effect after 6 days cumulative exposure to outdoor Tapp $\mathrm{p}_{\max }$ in the cold period, contrary to a large European study that observed associations up to CA15 [13]. Possible reasons for this inconsistency may be differences in population demographics, exposure conditions and the efficiency of the health care system.

Advantages of our study include accurate data on meteorological, air pollution and health outcome data [33,34]. Some disease misclassification is possible, but it is unlikely to be related to temperature. Another advantage is that similar results were in general observed for the association in the case-crossover and GAM analyses. The case-crossover design has some advantages over the Poisson time-series design. In Poisson time-series regression analysis, the population at risk must be very large relative to the daily number of events and the composition and size of the population at risk must not co-vary with the exposure of interest. The later assumption may not be fully met whenever the susceptible portion of the total population at risk may be increased by the cumulative effects of prior exposures or decreased by the adverse effects of prior exposures (harvesting). The case-crossover design avoids both problems as the outcome is on an individual level and not a population level (daily number of events).

One study limitation is the assumption that the outdoor temperature, humidity and air pollution measured at one site is the same across Copenhagen or even the same for each person. It is anticipated that such misclassification is more pronounced among the elderly and other frail groups who generally spend most of their time indoors. This misclassification is non-differential and should bias the effect estimates towards the null. Another limitation is that ozone data were missing for a large number of days in the period 1999-2006 and were thus not used in the analyses. Ozone is a potentially important confounder to heat effects [4].

Our results support the notion that moderate changes in ambient temperature are associated with impacts on human health even in a cool temperate climate. This association (assumed to be causal) is complex and depends on the specific health outcome (death or hospital admission), population characteristics (age, sex, SES), exposure conditions and the efficiency of the health care system, which all vary with time [1]. The results of this and many similar studies on temperature (and other key climate change factors) and health can thus not be extrapolated infinitely into the future without 
considering major uncertainties regarding changes in populations, the rate and intensity of projected climate change and adaptation, as stressed by the IPCC [1].

\section{Conclusions}

A moderate temperature increase had a protective effect on CVD mortality and hinted towards a slight increase in RD mortality during the warm period. In the colder months only protective effects were observed, although not statistically significant. Our results confirm that not only heat waves, but even moderate changes in ambient temperature in a Scandinavian city are associated with certain cause-specific mortality.

\section{Acknowledgments}

This work was commissioned and partially funded by the Danish National Board of Health and the Danish Research Councils. The authors would like to thank Martin Hvidberg (The National Survey and Cadastre, Copenhagen, Denmark) for his assistance in setting up the SES variable. We acknowledge the Danish Environmental Protection Agency for funding of the air pollution and meteorological measurements as part of the Danish Air Quality Monitoring Programme. Gratitude is also expressed towards the National Serum Institute for providing the influenza epidemic data. Preliminary results have been presented as an oral presentation at the 21 st International Society of Environmental Epidemiology Conference, Dublin, Ireland, 25-29 August 2009.

\section{Conflict of Interest}

No competing interests are declared.

\section{References}

1. Contribution of Working Group II to the Fourth Assessment Report of the Intergovernmental Panel on Climate Change, 2007; Parry, M.L., Canziani, O.F., Palutikof, J.P., van der Linden, P.J., Hanson, C.E., Eds.; Cambridge University Press: Cambridge, UK and New York, NY, USA, 2007; Available online: http://www.ipcc-wg2.gov/publications/AR4/index.html (accessed on 17 August 2011).

2. Kovats, R.S.; Hajat, S. Heat stress and public health: A critical review. Ann. Rev. Public Health 2008, 29, 41-55.

3. Basu. R.; Samet, J.M. Relation between elevated ambient temperature and mortality: A review of the epidemiologic evidence. Epidemiol. Rev. 2002, 24, 190-202.

4. Basu, R. High ambient temperature and mortality: A review of epidemiologic studies from 2001 to 2008. Environ. Health 2009, 8, doi:10.1186/1476-069X-8-40.

5. Braga, A.; Zanobetti, A.; Schwartz, J. The effect of weather on respiratory and cardiovascular deaths in 12 US cities. Environ. Health Perspect. 2002, 110, 859-863.

6. Medina-Ramon, M.; Zanobetti, A.; Cavanagh, D.P.; Schwartz, J. Extreme temperatures and mortality: Assessing effect modification by personal characteristics and specific cause of death in a multi-city case-only analysis. Environ. Health Perspect. 2006, 114, 1331-1336. 
7. Barnett, A.G. Temperature and cardiovascular deaths in the US elderly: Changes over time. Epidemiology 2007, 18, 369-372.

8. Nafstad, P.; Skrondal, A.; Bjertness, E. Mortality and temperature in Oslo, Norway, 1990-1995. Euro. J. Epidemiol. 2001, 17, 621-627.

9. Näyhä, S. Heat mortality in Finland in the 2000s. Int. J. Circum. Health 2007, 66, 418-424.

10. Rocklöv, J.; Forsberg, B. The effect of temperature on mortality in Stockholm 1998-2003: A study of lag structures and heatwave effects. Scand. J. Public Health 2008, 36, 516-523.

11. Reichert, T.A.; Simonsen, L.; Sharma, A.; Pardo, S.A.; Fedson, D.S.; Miller, M.A. Influenza and the winter increase in mortality in the United States, 1959-1999. Am. J. Epidemiol. 2004, 160, 492-502.

12. Eurowinter Group. Cold exposure and winter mortality from ischaemic heart disease, cerebrovascular disease, respiratory disease, and all causes in warm and cold regions of Europe. Lancet 1997, 349, 1341-1346.

13. Analitis, A.; Katsouyanni, K.; Biggeri, A.; Baccini, M.; Forsberg, B.; Bisanti, L.; Kirchmayer, U.; Ballester, F.; Cadum, E.; Goodman, P.G.; et al. Effects of cold weather on mortality: Results from 15 European cities within the PHEWE project. Am. J. Epidemiol. 2008, 168, 1397-1408.

14. O'Neill, M.S.; Zanobetti, A.; Schwartz, J. Modifiers of the temperature and mortality association in seven US cities. Am. J. Epidemiol. 2003, 157, 1074-1082.

15. Stafoggia, M.; Forastiere, F.; Agostini, D.; Biggeri, A.; Bisanti, L.; Cadum, E., Caranci, N.; de'Donato, F.; De Lisio, S.; De Maria, M.; et al. Vulnerability to heat-related mortality: A multicity, population-based, case-crossover analysis. Epidemiology 2006, 17, 315-323.

16. Ellermann, T.; Nordstrøm, C.; Brandt, J.; Christensen, J.; Ketzel, M.; Jensen, S.S. The Danish Air Quality Monitoring Programme. Annual Summary for 2010, Technical Report No. 836; National Environmental Research Institute, Aarhus University: Aarhus, Denmark, 2011.

17. Barnett, A.G.; Tong, S.; Clements, A.C.A. What measure of temperature is the best predictor of mortality? Environ. Res. 2010, 110, 604-611.

18. Michelozzi, P.; Accetta, G.; De Sario, M.; D’Ippoliti, D.; Marino, C.; Baccini, M.; Biggeri, A.; Anderson, H.R.; Katsouyanni, K.; Ballester, F.; et al. High temperature and hospitalizations for cardiovascular and respiratory causes in 12 European cities. Am. J. Respir. Crit. Care Med. 2009, 179, 383-389.

19. Danish Health Review for Regions and Communes. Sundhedsprofil for Region og Kommuner. 2008; Forskningscenter for Forebyggelse og Sundhed: Glostrup, Denmark, 2008. Available online: http://www.regionh.dk/NR/rdonlyres/8DC6D62D-DBC3-4219-8B1E-6113226066E9/0/ Sundhedsprofil2008_for_RegionH.pdf (accessed on 17 August 2011) (in Danish).

20. Maclure, M. The case-crossover design: A method for studying transient effects on the risk of acute events. Am. J. Epidemiol. 1991, 133, 144-153.

21. Bateson, T.F.; Schwartz, J. Control for seasonal variation and time trend in case-crossover studies of acute effects of environmental exposures. Epidemiology 1991, 10, 539-544.

22. Lee, J.T.; Kim, H.; Schwartz, J. Bidirectional case-crossover studies of air pollution: Bias from skewed and incomplete waves. Environ. Health Perspect. 2002, 108, 1107-1111.

23. Bateson, T.F.; Schwartz, J. Selection bias and confounding in case-crossover analyses of environmental time-series data. Epidemiology 2001, 12, 654-661. 
24. Levy, D.; Lumley, T.; Sheppard, L.; Kaufman, J.; Checkoway, H. Referent selection in case crossover analyses of acute health effects of air pollution. Epidemiology 2001, 12, 186-192.

25. Andersen, Z.J.; Wahlin, P.; Raaschou-Nielsen, O.; Scheike, T.; Loft, S. Ambient particle source apportionment and daily hospital admissions among children and elderly in Copenhagen. $J$. Expo. Sci. Environ. Epidemiol. 2007, 17, 625-663.

26. Anderson, H.R.; Atkinson, R.W.; Peacock, J.L.; Marston, L.; Konstantinou, K. Meta-Analysis of Time Series Studies and Panel Studies of Particulate Matter (PM) and Ozone ( $\left.\mathrm{O}_{3}\right)$. 2004; World Health Organization: Copenhagen, Denmark, 2004; Available online: http://www.euro.who.int/ data/assets/pdf_file/0004/74731/e82792.pdf (accessed on 17 August 2011).

27. European Commission Environment DG. Directive on Ambient Air Quality and Cleaner Air for Europe (Directive 2008/50/EC); European Commission Environment DG: Brussels, Belgium, 2008; Available online: http://ec.europa.eu/environment/air/quality/legislation/existing_leg.htm (accessed on 17 August 2011).

28. Mercer, J.B. Cold-An underrated risk factor for health. Environ. Res. 2003, 92, 8-13.

29. Baccini, M.; Biggeri, A.; Accetta, G.; Kosatsky, T.; Katsouyanni, K.; Analitis, A.; Anderson, H.R.; Bisanti, L.; D'Ippoliti, D.; Danova, J.; et al. Heat effects on mortality in 15 European cities. Epidemiology 2008, 19, 711-719.

30. Baccini, M.; Tom, K.; Biggeri, A. Impact of heat on mortality in 15 European cities: Attributable deaths under different weather scenarios. J. Epidemiol. Community Health. 2011, 65, 64-70.

31. O'Neill, M.S.; Ebi, K.L. Temperature extremes and health: Impacts of climate variability and change in the United States. J. Occup. Environ. Med. 2009, 51, 13-25.

32. McArthur, K.; Dawson, J.; Walters, M. What is it with weather and stroke? Expert Rev. Neurotherap. 2010, 10, 243-249.

33. Mathers, C.D.; Fat, D.M.; Inoue, M.; Rao, C.; Lopez, A.D. Counting the dead and what they died from: An assessment of the global status of cause of death data. Bull. World Health Organ. 2005, 83, 171-177.

34. Helweg-Larsen, K. The Danish register of causes of death. Scand. J. Public Health 2011, 39 (Suppl. 7), 26-29.

(C) 2011 by the authors; licensee MDPI, Basel, Switzerland. This article is an open access article distributed under the terms and conditions of the Creative Commons Attribution license (http://creativecommons.org/licenses/by/3.0/). 